\title{
El ideal ético más alto. Neokantismo y protección internacional de los derechos humanos
}

\author{
AGUSTÍN E. FERRARO \\ Universidad de Buenos Aires
}

Introducción

La mayor parte de los antiguos dictadores de Chile, Argentina y otros países latinoamericanos han logrado escapar al castigo que les hubiera correspondido por sus crímenes contra la humanidad. Algunos, como Pinochet, ni siquiera pudieron ser sentenciados y todavía consiguen burlar a la justicia extraterritorial simulando de manera más o menos convincente enfermedades físicas y mentales. Otros, como los dictadores argentinos y sus cómplices, fueron en algunos casos juzgados y condenados en sus países, pero se beneficiaron con indultos o con leyes que eximen de responsabilidad en el supuesto de crímenes cometidos en cumplimiento de órdenes dadas por oficiales superiores ${ }^{1}$.

Los antiguos dictadores han logrado estas formas de impunidad, en sus propios países, a través de los mismos mecanismos con los cuales ejercieron el poder en el pasado: la violencia y la intimidación contra toda una sociedad, ya sea de manera directa o más o menos velada. Sublevaciones, atentados, planteos, amenazas y otros actos de este tipo han hecho que la voluntad general de hacer justicia se viera repetidamente frustrada.

Hubiera podido suponerse que el juzgamiento extraterritorial de los antiguos dictadores de Chile y Argentina, que lleva adelante desde hace algún tiempo el juez español Baltasar Garzón, seria saludado por los partidarios de la democracia de estos países y de todo el mundo. Ni el juez Garzón ni las otras instituciones del Estado español pueden ser, en efecto, seriamente intimidadas o amenazadas por los antiguos dictadores latinoamericanos o sus cómplices, lo que asegura, por fin, un juicio justo y el cumplimiento de la condena si los criminales son apresados.

El apoyo de los partidarios de la democracia al juzgamiento extraterritorial de los crimenes contra la humanidad no fue, sin embargo, unánime. Cuatro presidentes o ex-presidentes democráticos de Chile y Argentina, a saber, Eduardo Frei, Ricardo Lagos, Raúl Alfonsín y Carlos Menem se opusieron con menor o mayor energía a los juicios extraterritoriales. En los contextos en que esas posiciones tuvieron un sustento argumental, un tópico que se ha hecho siempre presente es la de la soberanía de cada Estado. En efecto, si bien los juicios que se realizaron en Chile o Argentina, o todavía se intentan realizar, estuvieron y están expuestos a toda una serie de obstáculos y limitaciones de acuerdo con el poder de intimidación que todavía conservan los militares (bastante grande en Chile, menos importante en Argentina) se ha querido enfatizar el carácter vinculante y definitivo de esos juicios, de modo que aceptar la jurisdicción extraterritorial de los tribunales españoles resultaría violatorio de la soberanía de los Estados latinoamericanos.?

En el presente trabajo quisiera analizar y discutir, por tanto, la noción de soberanía 
y el grado en que esta propiedad o atribución de los Estados se pone en juego o es afectada por el juzgamiento extraterritorial de los crimenes contra la humanidad.

A los fines del análisis, voy a destacar un aspecto relativamente ignorado de la obra del jurista austríaco Hans Kelsen, a saber, su desarrollo en el plano de la teoría jurídica de la noción ética de humanidad, tal como la había expuesto el fundador del neokantismo de Marburgo, Hermann Cohen, cuya influencia sobre la obra del primero se tiende, en mi opinión, a subestimar. A partir de la obra de los dos autores puede mostrarse con gran claridad la contraposición entre una noción (objetivista) de humanidad y la noción (subjetivista) de soberania, que no puede sino considerarse un obstáculo para el desarrollo del derecho internacional. Voy a analizar, en el primer punto, la crítica de Kelsen a la noción de soberanía, para pasar, en el segundo punto, a una breve exposición de la idea de humanidad desarrollada por Cohen. En las conclusiones del trabajo volveré sobre algunas cuestiones políticas y psicológicas mencionadas en esta Introducción e intentaré extraer algunas conclusiones sobre la influencia de la ética de Cohen en la teoría pura del derecho de Kelsen.

\section{Hans Kelsen: ética y crítica de la soberanía}

La posición más decidida del siglo XX en favor de una centralización de los organismos del derecho internacional es sostenida por Hans Kelsen, quien fuera calificado como "el jurista del siglo". Kelsen intenta disipar el recelo con que este tipo 'de centralización es generalmente contemplada, debido a la tendencia, que ella representa, hacia la formación de instituciones propias de un Estado mundial. En una tradición de pensamiento que tiene a Kant como su exponente más ilustre, se afirma que un Estado de esa naturaleza no podría sino conducir al abuso de poder. ${ }^{3}$ El error en que incurren los partidarios de esta posición es expuesto por Kelsen de una manera muy directa:

Que la formación de organismos diferenciados dentro de la comunidad jurídica internacional pueda conducir al peligro del abuso fáctico del poder, y de aquí a la opresión de un sujeto por parte de los otros, de la misma forma en que esto puede ser el caso dentro de la comunidad de un Estado singular, no debe negarse de ninguna manera $¿$ Pero se puede acaso afirmar la igualdad fáctica de los Estados, y desmentir la violación fáctica de los Estados más pequeños por parte de las grandes potencias, se puede considerar seriamente al principio de la igualdad de los Estados como una regla del ser social? Como principio jurídico, sin embargo, no sufre ninguna amenaza por la formación de órganos centrales $¿$ Resulta la igualdad jurídica de todos los ciudadanos acaso anulada mediante la presencia de la organización estatal, o más bien, justamente a través de esta organización, garantizada? ${ }^{4}$

Una declaración tan política de Kelsen resulta sorprendente, sin duda, desde el momento en que estamos habituados a considerar a este autor como un partidario de la neutralidad valorativa en las ciencias sociales y jurídicas. Particularmente entre autores en lengua castellana, en efecto, se acostumbra sencillamente identificar la "pureza" metodológica, que sostenía Kelsen, con el postulado metodológico de la neutralidad valorativa. ${ }^{5}$

Independientemente de esta discusión, sobre la que volveremos, debe observarse que la actitud recelosa ante el posible desarrollo jurídico hacia un Estado mundial no deja de ser el último punto de apoyo racional de la noción de soberanía. De lo contrario, la representación de la soberanía de los Estados carecería de otro fundamento que no sea su realidad actual. Así por ejemplo, cuando Pedro Daza Valen- 
zuela, director del Instituto "Libertad", de Santiago de Chile, afirma que la detención de Pinochet es violatoria del derecho internacional y que, con ella, el juez Garzón afecta la soberanía de Chile y compromete la responsabilidad del Estado español, ${ }^{6}$ todo su argumento reposa o bien en la mera proclamación de la soberanía como un dato de la realidad o bien en que se estaría aquí cometiendo una violación de la igualdad jurídica de Chile ante otros Estados.

Según Daza Valenzuela la define, la soberanía consiste en un conjunto de competencias que el derecho internacional atribuye al Estado y que son "ejecutables en un plano de independencia e igualdad respecto de otros Estados". ${ }^{7}$ En el caso que nos ocupa, se trataria de la competencia de ejercer su jurisdicción, esto es, administrar justicia en su territorio, respecto de los ciudadanos y de los extranjeros. En cuanto asociada con la idea de la independencia, la noción de soberanía es considerada por Daza Valenzuela un garante de la igualdad jurídica entre los Estados, desde el momento en que nada puede realizarse en contra de la voluntad de cada uno de éstos, por ser soberanos. Con lo dicho se asegura, teóricamente, la autonomía de cada Estado y se evitan abusos de poder, los que deberíamos suponer inevitables, según esta forma de pensar, si se renuncia a la soberanía en aras del desarrollo del derecho internacional.

Ahora bien, Kelsen observa con gran lucidez que, en cuanto supuesto de hecho, la tesis de la soberania es insostenible. En efecto, la independencia fáctica de los Estados es violada todo el tiempo por los más poderosos de entre ellos. La pérdida de soberania que representa el juzgamiento extraterritorial de crimenes contra la humanidad no afecta en absoluto esta realidad de la política internacional. Más bien es al contrario: el avance hacia la centralización de funciones judiciales no conspira contra la igualdad jurídica de las personas, sino que, tanto como ocurre en el marco de un Estado particular, es la única forma de garantizarla en los hechos. Si desaparece el ordenamiento jurídico en un territorio, esto es el Estado, es obvio que los más fuertes impondrản su voluntad sin obstáculos. Los organismos jurídicos centralizados, en especial la administración de justicia, tienen la función de impedir que ocurra una situación tal (aunque a veces no lo consigan).

Puede decirse, entonces, que el fundamento más importante de la soberanía, cual es su contribución a preservar la igualdad jurídica entre los Estados, no es dañado de ninguna manera por el juzgamiento extraterritorial de crímenes contra la humanidad. Concedamos que la soberanía de Chile, en cuanto tal, se ha visto perjudicada en el caso del juzgamiento extraterritorial de Pinochet. Sin embargo, que la soberanía de un Estado resulte afectada no es un argumento, en sí mismo, en contra del juzgamiento extraterritorial, a menos que hagamos de la soberanía un dogma de fe, que no ha de ser sopesado frente a otras consideraciones. Puesto que la soberanía no es un valor absoluto, sino una propiedad que ha de contribuir, como queda dicho, a preservar la igualdad jurídica de los Estados (en cuanto puede tener algún fundamento), debe concluirse que tiene que ser postergada cuando, como en este caso, lo que está en juego es el cumplimiento de normas jurídicas que penan los crímenes en contra de la humanidad. Porque el fundamento de la soberanía, vale la pena repetirlo, no es afectado aquí en absoluto. En tanto los crímenes contra la humanidad son justamente castigados y en cuanto se propende a formar instituciones judiciales mundiales (esto es, extraterritoriales), la igualdad juridica de los Estados no es dañada sino que, por el contrario, se contribuye a conformar los instrumentos que pueden garantizarla.

Sin embargo, como también lo señala Daza Valenzuela, ${ }^{8}$ el tribunal del juez Bal- 
tasar Garzón no tiene un carácter internacional. Esta circunstancia proporciona otro importante argumento en contra del presente juzgamiento extraterritorial de los dictadores latinoamericanos. Se presupone que, de acuerdo con el modelo del Estatuto de Roma, ${ }^{9}$ los diferentes Estados deberían suscribir un convenio por el cual renuncian a su jurisdicción territorial soberana ante ciertos crímenes específicamente determinados, que pueden ser entonces juzgados por tribunales internacionales, que no se subordinan a ningún Estado particular firmante del convenio.

Al juzgamiento de los dictadores latinoamericanos por el juez Baltasar Garzón, en cambio, no le ha precedido ninguna renuncia de jurisdicción soberana por parte de Chile o Argentina. Esto es lo que hace al caso especialmente irritante para algunos y especialmente interesante para otros. Pues los procedimientos de tipo convencional, como el que lleva al Estatuto de Roma, permiten mantener la ficción (jurídica) de la completa soberanía de cada uno de los Estados contratantes. ${ }^{10}$ En este supuesto, en efecto, cada uno de los Estados renuncia, por anticipado, al ejercicio de su jurisdicción territorial respecto a determinados crimenes, que serán juzgados por la Corte Penal Internacional. En el caso del juez español, en cambio, el procedimiento es independiente de la voluntad del Estado al que los acusados pertenecen.

Con esto llegamos a un punto decisivo, que concierne a lo más profundo de la noción de soberania: se trata de la idea de que un Estado no está jurídicamente obligado sino en cuanto manifiesta su voluntad de obligarse y hasta tanto no manifieste la voluntad de cesar en su obligación. Por esto es que la Corte Penal Internacional, de acuerdo con el Estatuto de Roma, solamente puede ejercer jurisdicción dado el caso de que hayan suscripto el Estatuto a) o bien el Estado del terri- torio donde se comete un crimen b) o bien el Estado al que pertenece el acusado. Se descartaron en cambio, durante la negociación, la posibilidad de ejercer una jurisdicción verdaderamente internacional o universal, así como la llamada "propuesta de Corea", que agregaba a los dos Estados mencionados c) el Estado de nacionalidad de las víctimas y d) el Estado donde el acusado es detenido.

Esta restricción hace del Estatuto de Roma un acuerdo plenamente voluntario para los Estados y conspira, sin duda, contra el juzgamiento extraterritorial de futuros jefes de Estado responsables de crímenes contra la humanidad o de sus cómplices, que es la hipótesis más grave y aquella que presta mayor relevancia a la creación de organismos centralizados del derecho internacional. Debe notarse, además, que un Estado que haya suscrito el Estatuto de Roma puede "denunciarlo" (lo que equivale, en la terminologia del derecho internacional, a declarar su voluntad de dejar de cumplirlo) cuando así lo crea conveniente (art. 127), con lo que el Estatuto deja de tener validez para ese Estado, si bien se establece el plazo de un año desde la denuncia hasta que el Estado queda libre de todas sus obligaciones relativas al Estatuto. Vale decir que, con esta única salvedad del plazo de un año hasta que la denuncia tiene pleno efecto, el Estado, según la ficción jurídica de la soberanía que mencionamos, solamente está obligado en cuanto manifiesta su voluntad de obligarse y mientras no cambie de opinión.

Bajo el presupuesto de la soberania del Estado, las normas del derecho internacional solamente se consideran válidas $u$ obligatorias para un Estado en cuanto éste "reconoce" las normas en cuestión (y mientras tanto siga teniendo intención de reconocerlas). Esta posición se corresponde, de acuerdo con Kelsen, con el subjetivismo de la teoria del conocimiento, que no reconoce la existencia de un mundo 
objetivo sino solamente en cuanto representación del sujeto. ${ }^{11}$ Por tanto, para quien adopta como perspectiva la soberanía del propio Estado, el derecho de éste adquiere una primacía por sobre todo otro ordenamiento jurídico, incluso el derecho internacional, pues la validez del último depende, como se dijo, del "reconocimiento" que le confiere el Estado desde donde parte la construcción.

Para Kelsen, el problema con la noción de soberanía y con su consecuencia directa, la primacía del orden jurídico del Estado soberano frente al derecho internacional, es que resultan, en última instancia, incompatibles con toda relación juridica y con la idea misma del derecho. La noción de que un Estado no está obligado jurídicamente sino porque lo quiere y mientras lo quiere equivale, en efecto, a la afirmación del pun to de vista de la fuerza. Se trata de un supuesto inherente al subjetivismo, que implica la negación del derecho y que Kelsen describe en los siguientes términos:

La tendencia subjetivista inherente a la teoría del predominio del orden jurídico estatal conduce, desde su posición fundamental, a la negación del derecho internacional y, desde aquí, a la negación de la idea jurídica (Negation der Rechtsidee) - por lo menos en esta esfera - y a la afirmación del puro punto de vista de la fuerza. Así como el mismo pensamiento, desarrollado consecuentemente en la esfera del derecho estatal, en cuanto predominio del individuo lleva a la negación del derecho, en general, y a la proclamación de la idea de la fuerza en toda la línea. ${ }^{12}$

Según ha sido expuesto, la noción de soberanía significa que un Estado no está sujeto a ninguna clase de obligación que no coincida con su voluntad. Pero esto constituye más bien, como señala correctamente Kelsen, una proclamación subjetivista de la propia fuerza. Que se trata aqui de una negación del derecho, en última instancia, puede notarse con claridad en cuanto extrapolamos las implicaciones de la soberanía al plano de un sistema jurídico estatal particular. En este caso, solamente vale como derecho para un individuo "soberano" lo que él quiere reconocer como tal y mientras lo quiera. La existencia de las obligaciones que se ha impuesto queda, por tanto, librada a su arbitrio del momento, lo que parece, en algún sentido, contradictorio. El derecho exige cierto grado de objetividad, es decir, independencia de la voluntad subjetiva del individuo. De lo contrario, la persona no está obligada por las normas jurídicas sino en cuanto coinciden con su voluntad, lo que no se diferencia del punto de vista de la fuerza, en donde los únicos obstáculos a la voluntad son obstrucciones de tipo causal y empírico.

En el sentido expuesto, el juzgamiento extraterritorial de los dictadores latinoamericanos, que lleva adelante el juez Baltasar Garzón, representa un estadio mucho más avanzado, en el desarrollo del derecho internacional, que el propio Estatuto de Roma de la Corte Penal Internacional. Este último, en efecto, se mantiene ligado a la representación de la soberanía, la que constituye el obstáculo más importante para el desarrollo del derecho internacional en cuanto ordenamiento jurídico de las relaciones entre los Estados.

Pero un ordenamiento jurídico no puede existir, como afirma Kelsen, si no es objetivo. La objetividad del derecho representa la superación de la perspectiva subjetiva de la propia fuerza y éste es el sentido más profundo, pero también más elemental, de la idea jurídica. Una tarea como la del juez Garzón y la de otros tribunales que llevan a cabo, espontáneamente, el ejercicio de la jurisdicción extraterritorial respecto a los crímenes contra la humanidad, sienta las bases prácticas y conceptuales que podrán permitir un día establecer la seguridad jurídica para todos los seres humanos, en cuanto personas de un ordenamiento de derecho internacional. El Tribunal Penal Internacional tiene que poder 
actuar con independencia del poder intimidatorio que los criminales contra la humanidad ejercen sobre las sociedades en donde han cometido sus crímenes y que obliga a éstas a indultar o a consentir en dichos crímenes, como en el caso de Latinoamérica. La idea de un Tribunal Penal Internacional podrá concretarse en plenitud cuando se supere la representación particularista y subjetivista de la soberanía de los Estados. A partir de ese momento, podrá decirse que la humanidad ha dejado de ser una idea abstracta para convertirse en la unidad jurídica de todos los seres humanos, cuyos derechos deben ser reclamables independientemente de la pertenencia a un Estado determinado.

El punto de vista del derecho no puede construirse a partir de la perspectiva excluyente de un sujeto o de un Estado. Para poder afirmar la validez objetiva del derecho internacional -que equivale, vale la pena subrayarlo, a su existencia como derecho-es necesario abandonar la perspectiva subjetivista de la soberanía y suponer, por el contrario, una pluralidad de Estados como personas jurídicamente iguales del derecho internacional, sujetas a un sistema jurídico objetivamente obligatorio para todas ellas (en este sentido, defiende Kelsen la primacia del derecho internacional). Puede pensarse, sin duda, que dicha suposición de una pluralidad de sujetos no carece de vinculación con una idea fundamental de la ética (que desarrollaremos en lo que sigue), lo que arroja dudas sobre la "pureza" de la teoría jurídica, según se interpreta habitualmente el pensamiento de Kelsen (tal y como si la pureza equivaliera a la neutralidad). Pero esto no es así. Por un lado, Kelsen afirma sin ninguna reserva que la hipótesis de la pluralidad de sujetos de derecho es, en efecto, una idea ética fundamental:

La representación de la coexistencia de una pluralidad de Estados, los que, a pesar de la diferencia fáctica en su tamaño, cantidad de población y medios coactivos efectivos, tienen el mismo valor desde el punto de vista jurídico y - con esferas de poder delimitadas recíprocamente - están unidos en algûn tipo de comunidad superior, es una idea eminentemente ética y uno de los pocos, realmente valiosos e indiscutidos componentes de la consciencia cultural moderna. Pero esta representación solamente es posible con ayuda de una hipótesis jurídica: que por sobre las entidades comunes (Gemeinwesen) que se consideran Estados se halla un ordenamiento jurídico que delimita en forma recíproca las esferas de validez de los Estados individuales [...] Y en la medida en que la primacía del derecho internacional cumple esta función, el concepto de derecho viene a ser realizado tanto en sentido formal como material: el derecho se convierte en la organización de la humanidad $y$, con esto, se vuelve uno con la idea ética más alta. ${ }^{13}$

La idea ética más alta, que también da su título al presente trabajo, es, como veremos en detalle en el próximo punto, la idea de humanidad. Se trata de la formulación de un pensamiento original de la obra de Hermann Cohen, que constituye, a la vez, una pieza clave de la ética neokantiana.

Por ahora, solamente quiero hacer notar que, por otro lado, la "pureza" de la teoría jurídica no sufre absolutamente ninguna desnaturalización, de acuerdo con Kelsen, cuando se muestra que determinadas instituciones jurídicas contienen supuestos éticos, los que forman sus condiciones trascendentales de posibilidad (éste es, como veremos, el método de la ética de Cohen). Según lo expuesto hasta aquí, dos puntos de vista excluyentes se diferencian en torno al problema del derecho internacional: en primer lugar, un punto de vista subjetivista, representado por la noción de soberanía, que conduce finalmente a la negación del derecho y a la afirmación del punto de vista de la fuerza. En segundo lugar, desarrolla Kelsen el 
punto de vista que denomina "objetivista" y "universalista", que define como el predominio del derecho internacional por sobre los sistemas jurídicos de los Estados individuales. Este punto de vista parte de un supuesto (a priori) que se identifica con la noción de humanidad.

La pureza de la teoría jurídica no queda afectada al mostrar los supuestos trascendentales de las dos diferentes perspectivas, subjetivista y objetivista. Pues en ningún momento adopta la teoría una postura prescriptiva. Vale decir, la teoría pura del derecho no fundamenta prescriptivamente ciertas normas, sino que muestra los supuestos éticos de las instituciones jurídicas existentes, o de su negación, tanto como el desarrollo y las consecuencias de ambas posiciones. Sin que esto signifique una ausencia de todo compromiso normativo, lo que sería metodológicamente imposible, la teoría jurídica de Kelsen evita la postulación y fundamentación especulativa de normas de la ética.

Así por ejemplo, cuando Kelsen señala que no habría una diferencia de naturaleza entre la comunidad jurídica internacional que hoy tenemos y un Estado mundial, puesto que éste último solamente se diferenciaría de la primera en su mayor grado de centralización de organismos jurídicos, observa:

No es en pro o en contra de alguna confesión política sino para enfrentar una crasa manipulación de la ciencia jurídica, a fin de preservar su pureza y con esto su honor, que se establece como resultado de estas investigaciones el que el ordenamiento jurídico internacional, sin el menor peligro para su naturaleza, puede también volverse una comunidad "organizada", un "Estado", en todos los sentidos posibles de esta palabra. ${ }^{14}$

Como se ve, hay en la posición de Kelsen una actitud en cierto sentido "neutral" ante normas éticas, pero que no guarda absolutamente ninguna relación con la "neutralidad valorativa" sostenida tanto por Max Weber como por el positivismo epistemológico. En estos dos casos, el fundamento de la neutralidad valorativa es una actitud escéptica ante las normas en general. Nada más lejos de la postura de Kelsen. La teoría pura del derecho procede a mostrar que determinadas normas éticas son condiciones de posibilidad del derecho $y$, solamente en este sentido, es "neutral" frente a ellas. Se trata de una metodología ética peculiar, que había sido desarrollada por el fundador del neokantismo de Marburgo, Hermann Cohen y que voy a exponer brevemente en el próximo apartado.

II. La intersubjetividad fundamental de Hermann Cohen

En 1876 obtiene Hermann Cohen su designación como Profesor Ordinario en la Universidad de Marburgo, momento fundador de la primera gran escuela neokantiana, que lleva el nombre de dicha universidad. La enseñanza y la metodología de trabajo de Cohen llegarian a distinguir al neokantismo en su conjunto. Si bien la obra de Kant le sirve como inspiración y base doctrinaria común, los resultados que se alcanzan van mucho más allá de la mera exégesis del filósofo de Königsberg, hasta adquirir el estatuto de sistemas filosóficos enteramente originales. Sin embargo, los neokantianos nunca dejaron de proclamar su adhesión a la filosofia crítica, lo que se traduce sobre todo en una cuidadosa reelaboración del método trascendental.

En el terreno de la ética y la filosofia jurídica, el pensamiento de Cohen se caracteriza por el intento de fundar la moral universalista de inspiración kantiana en una base radicalmente intersubjetiva. De la misma forma que en su filosofía teórica, ${ }^{15}$ renuncia Cohen, para esto, al sujeto de la filosofía de la consciencia, desde el cual no pueden sino construirse sistemas 
filosóficos monológicos, en última instancia solipsistas. En el lugar de la consciencia psicológica o trascendental, va a proponer como sujeto de la moralidad una instancia conceptual que denomina autoconsciencia, y que define como la consciencia del otro. Desde aquí, emprende Cohen un amplio y minucioso proyecto de fundamentación ética del socialismo, corriente política que, desde su punto de vista, resulta la consecuencia necesaria y la culminación de toda filosofía práctica de inspiración kantiana.

Ahora bien, un rasgo metodológico central de la ética de Cohen consiste en su propuesta de aplicar el método trascendental en la esfera práctica de la razón, tanto como Kant lo aplicó a la filosofía teórica. Por esto es que Cohen intenta demostrar trascendentalmente su tesis ética, que postula, como se dijo, el carácter fundamentalmente intersubjetivo de la moralidad. Dicha tesis, en otras palabras, no se queda en una mera propuesta edificante o sugestiva, sino que Cohen procede a mostrar que la intersubjetividad fundamental es la condición de posibilidad de una realidad determinada. La realidad, o el factum de que parte esa demostración trascendental, es la realidad jurídica, en cuanto mediación entre los conceptos puros de la ética y la realidad social.

Cohen quiere solucionar así lo que le parece una falta de coherencia en el sistema de la filosofia crítica: que Kant no aplicó en la razón práctica el método trascendental tal como lo aplicó en la razón teórica. De la misma manera en que, a través del método trascendental, enlaza Kant la lógica con la ciencia natural, debería haber postulado a las ciencias sociales como fundamento y punto de partida para la construcción de una ética trascendental. Sin dejar de ser universalista, la ética no puede ser, para Cohen, independiente de la realidad social e histórica.

Cohen hace suya la definición socrática de la ética como la doctrina del concepto del hombre. Sin embargo, no son las determinaciones particulares de la humanidad aquello que se propone discutir bajo dicha denominación, sino que, desde un primer momento, su interés se dirige a las nociones de individuo, pluralidad y universalidad de los hombres, desde las cuales, especialmente a través de la relación entre la primera y la última, elabora su concepción de la intersubjetividad. En otras palabras, la filosofía práctica de Cohen no es una antropología. Su intento es, no sólo desarrollar una concepción de la intersubjetividad, sino asegurarse de que la misma adquiera un rol constitutivo para la ética $y$, a través de ésta, para la filosofía jurídica, para la política y para las ciencias sociales.

Dicho de manera simplificada, Cohen entiende a la intersubjetividad como una correlación entre el individuo y la universalidad de los hombres, mediada por el concepto del otro. Los tres términos lógicos, individuo, pluralidad y universalidad de los hombres, son expuestos por Cohen a través de un análisis de la significación de la propia palabra "hombre". La palabra se usa tanto para referirse al individuo (Einzelmensch), como para referirse a una pluralidad (Mehrheit). Pero, a su vez, el concepto de la pluralidad de los hombres se enlaza con el de la universalidad ( $A l l-$ heit), que conforma, en su grado máximo, la humanidad.

El sujeto de la razón práctica no puede ser, en opinión de Cohen, el individuo pues una ética que se organice en torno al individuo, sea empírico o trascendental, resultaría incapaz de dar cuenta del problema del otro. El término que establece la oposición más completa con el individuo es el de la universalidad de los hombres. La universalidad es definida por Cohen como un tipo de asociación, caracterizada por constituir la unidad de un número ilimitado de individuos. Esto no significa, por supuesto, que para dicho tipo de asociación no pueda establecerse, en un momen- 
to dado, la cantidad precisa de sus miem bros: el punto es que no hay restricciones empíricas o conceptuales preestablecidas de esa cantidad, restricciones como podrían ser la raza, la religión, el idioma, etc., las que aparecen como determinantes, en cambio, de otras formas asociativas como pueden ser el la raza, el pueblo, la comunidad, la iglesia, etc. En otras palabras, la unidad que subyace a la universalidad es irrestricta. Esto hace que la universalidad propiamente dicha no pueda ser sino, en última instancia, la humanidad.

Ambos términos contrapuestos, individuo y universalidad, tienen que ponerse en una correlación, frente a la imposibilidad de construir la ética sobre la base del primero de ellos. La correlación del individuo con la universalidad es establecida por Cohen mediante una concepción a priori de la intersubjetividad. La idea de la intersubjetividad a priori es, dicho de forma simplificada, la siguiente: el otro debe ser pensado en forma originaria, juntamente con el yo. Es decir, el yo no debe poseer ninguna clase de prioridad ontológica o epistemológica.

De aquí resulta la objeción principal contra una razón práctica cuyo sujeto fuera el individuo. Al individuo puede postulárselo en forma independiente y separada de otros individuos. Bajo este punto de vista, el otro individuo es, en el mejor de los casos, mero producto de la experiencia: el yo percibe un entorno, y encuentra allí a otros hombres. Esto es propio del sujeto del conocimiento, en el idealismo psicológico, y sería un error trasladarlo a la ética. Cohen opina que este error fue cometido por Fichte, quien postula en el plano ético al yo como la autoconsciencia, a la que se enfrenta el no-yo. El no-yo es en Fichte la cosa, el objeto en general, todo objeto. ${ }^{16}$ Pero no puede construirse una ética partiendo del yo monológico del sujeto de conocimiento, que es caracteristico del idealismo, pues el otro resulta entonces un derivado, un producto secundario ante la primacía del yo. Este no- yo, como objeto derivado y empírico que se aparece en la consciencia del yo, viene a ser habitualmente representado como el prójimo ( $\mathrm{Ne}$ benmensch). De acuerdo con Cohen, la representación empírica del prójimo tiene que ser abandonada, desde el punto de vista de la ética, para ser substituida por el concepto de un otro, que ya no sea entendido como derivado del yo, sino puesto en una posición tan fundamental como la de éste:

El prójimo es pensado como un prójimo, o más bien representado como uno de muchos prójimos. Si partimos en cambio del concepto, correctamente entendido, del no- yo, aparece en lugar del prójimo el concepto más preciso del otro. El otro no es un otro cualquiera; se encuentra en la correlación precisa, más aún en la relación de continuidad con el yo. El otro, el alter ego, es el principio [Ursprung] del yo. ${ }^{17}$

El prójimo no se concibe de manera precisa, justamente, por tratarse de una representación empírica. En este sentido, un prójimo en particular es siempre uno de los muchos objetos de su clase susceptibles de representación.

Ahora bien, desde Kant, el idealismo trascendental concibe al yo de la razón teórica de manera a priori. ${ }^{18} \mathrm{El}$ yo de la percepción, en efecto, no puede ser pensado, él mismo, como una percepción. Para Cohen, en el contexto de la razón práctica, tanto el yo como el no-yo deben concebirse de esta forma a priori. Es decir, el "concepto correctamente entendido" del no- yo es el concepto a priori del otro en general. Este otro es el principio (Ursprung) del yo en el sentido de que, en la ética, la construcción teórica del yo no puede ser independiente del otro. De esta forma, el otro opera como un principio trascendental del sujeto, como su condición de posibilidad. El sujeto de que se trata, claro está, ha dejado de ser el individuo empírico, el yo 
monológico de la consciencia teórica, y Cohen lo denominará, de ahora en adelante, la autoconsciencia (Selbstbewusstsein)

La autoconsciencia se constituye en la correlación del uno y del otro, como autoconsciencia de la pura voluntad, lo que equivale a decir como autoconsciencia de la razón práctica pura. La pureza de que se trata aquí consiste, tanto como en el conocimiento teórico, en el nivel trascendental de la formulación. Cohen utiliza el adjetivo "puro" para denominar la esfera de lo trascendental en general. La misma denominación es adoptada por Kelsen a partir de 1920, dando origen así a su teoría "pura" del derecho. Tiempo después reconocía Kelsen haber obtenido a partir de la obra de Cohen el "punto de vista decisivo en la teoría del conocimiento", ${ }^{19}$ lo que confirma que, con la denominación de "pura", pretendia Kelsen hacer evidente su deuda hacia Cohen, por lo menos en el terreno metodológico. ${ }^{20}$ En lo que hace al plano substantivo de la ética, voy a intentar verificar la vinculación entre ambos autores en las conclusiones del presente trabajo.

Ahora bien, debe subrayarse que las afirmaciones sobre la autoconsciencia hechas hasta ahora son, desde el punto de vista del método de Cohen, completamente especulativas. La idea de una intersubjetividad a priori, en cuanto presuposición del otro como condición de posibilidad del yo, puede resultar sugestiva o quizás edificante, pero no se ha demostrado en absoluto que tal forma de la intersubjetividad, a la que Cohen denomina autoconsciencia, sea posible, ni mucho menos real. Ahora es que la idea de aplicar el método trascendental a la filosofía práctica se pone a prueba. Cohen ha de intentar una deducción trascendental de la autoconsciencia, en donde se muestra que la autoconsciencia es una condición de posibilidad del factum del derecho. Se trata de mostrar al con- cepto de la ética (la autoconsciencia) como condición de posibilidad de un concepto de la ciencia jurídica (la persona), lo cual equivale, desde el punto de vista del método trascendental, a mostrar que ese concepto de la ética es condición de posibilidad de una realidad jurídica. Al probar que el concepto de la ética es la condición de posibilidad de la realidad jurídica, la que constituye un factum que no requiere demostración, queda demostrada la validez del concepto. ${ }^{21}$

Lamentablemente, no dispongo del espacio suficiente como para desarrollar en detalle la deducción trascendental de la autoconsciencia, una argumentación no exenta de complejidades..$^{22} \mathrm{Me}$ limitaré a señalar que Cohen inicia su argumento a partir de la noción de contrato, remontándose hasta la figura romana de la universitas, donde se manifiesta ya la universalidad como unidad ideal de una pluralidad de personas.

La argumentación de Cohen tiene como un punto de apoyo principal el hecho de que la persona jurídica, fundada en el contrato, pueda entenderse como un esquema de acción directamente enlazada con su manifestación en el lenguaje, esto es, un esquema de interpretación. Cohen intenta demostrar que este esquema de interpretación tiene como condición de posibilidad la relación entre el yo y el otro que se trataba de fundar trascendentalmente (la autoconsciencia, en cuanto relación entre el yo y el otro). Voy a citar uno de los pasajes concluyentes de la deducción:

Y ahora consideremos el progreso que, desde el punto de vista del contrato, se puede desarrollar para el concepto del prójimo. Hasta ahora aparecía el no-yo solamente como el otro del yo. No como un otro, sino como el otro [...] El contrato es una pretensión; una pretensión del derecho, que yo planteo al otro. La acción legal en general (actio) es, ciertamente, una tal pretensión jurídica, por lo menos como pretensión judicial. El contrato hace ahora de la pretensión 
(Anspruch) la ilocución (Ansprache), Y por esto se convierte el otro en yo y tú. Tú no es él. El sería el otro. El corre peligro de ser tratado también como eso. Tú y yo se corresponden por completo. Yo no puedo decir tú, sin referirte a mí; sin unirte, en esta relación, con el yo [...] Este es el progreso del otro hacia el tú. Y este progreso es confirmado por la ficción jurídica. Así se acredita la persona jurídica como la persona moral. ${ }^{23}$

El no- yo había sido postulado por Cohen como el otro a priori, criticando la tendencia (idealista) a considerar al otro como un producto de la experiencia del yo, como prójimo. El no- yo pasaba a ser considerado, entonces, como el otro en general. De lo que se trata, consecuentemente, es de probar que el otro se encuentra en una relación de correlación con el yo, de forma que ambos constituyen una unidad de tipo intersubjetivo, a la que Cohen, como se dijo, da el nombre de autoconsciencia.

La extensión intersubjetiva de la autoconsciencia se manifiesta en la persona jurídica, que es la unidad real de una pluralidad de individuos. Resulta de la naturaleza lingüistica de la acción legal, que es también un acto de habla, una ilocución (Ansprache), ${ }^{24}$ que, en la relación contractual, la voluntad del ego no pueda concebirse sin un alter.

La voluntad del sujeto de derecho presupone entonces un otro como alter, como interlocutor de la acción legal, la que tiene, como queda dicho, una naturaleza lingüistica. El concepto de sujeto presupuesto por la persona jurídica no puede pensarse entonces como monológico, sino como la correlación de ego y alter. El sujeto de la ética, la autoconsciencia, que no es otra cosa que dicha correlación, se muestra así como condición de posibilidad de la persona jurídica.

Finalmente, la ética de Cohen concluye en un programa político basado en la universalidad del concepto de Estado, en un sentido que no hemos considerado hasta ahora. Para Cohen, el ideal del Estado debe ser entendido de manera independiente respecto a cualquier Nación y cualquier pueblo particular. Lo que se propone es defender una forma de organización democrática y socialista, la cual sólo puede realizarse como un ideal de la humanidad en su conjunto. Este pensamiento es anunciado por Cohen ya en la "Introducción" a la Ética de la pura voluntad, con lo que dicha tesis adquiere el carácter de programa central de la filosofía práctica de Cohen:

Se habrá de mostrar que la oposición entre Estado y humanidad es sólo aparente. En la medida en que buscamos fundar la unidad del hombre en la unidad del Estado, no disociamos, por así decirlo, al hombre de la humanidad; sino que más bien nos apoderamos con esto de la herramienta apropiada para llevar el antagonismo entre el hombre individual y la humanidad universal a una verdadera superación. $Y$ la humanidad se vuelve sólo por este camino metodológico una idea ética; mientras que, de lo contrario, no pasa de ser una creencia piadosa, que, en el mejor de los casos, se funda después en su contrario, esto es, en un concepto de la ciencia natural; pues el principio teleológico de la unidad del género humano no es realmente más que esto. ${ }^{25}$

La novedad de la tesis de Cohen consiste en sostener que, en el estado de naturaleza de las relaciones internacionales fundadas en la soberanía de los Estados, carecen éstos de personalidad jurídica. Vale decir, como sostendrá también Kelsen, que el Estado sólo puede tener una naturaleza jurídica cuando se subordina al orden jurídico internacional:

Sin embargo, el Estado logra representar la universalidad tan sólo porque está ordenado concéntricamente respecto a la federación de Estados de la humanidad [...] el Estado nacional mismo no debe formar ninguna contradicción 
frente a la federación de Estados de la humanidad. Por detrás del derecho de los Estados individuales se encuentra el derecho internacional, y, verdaderamente, no en la distancia nebulosa, sino como el ideal del Derecho. ${ }^{26}$

En este pasaje indica Cohen la conclusión de su argumentación acerca de la universalidad del lazo jurídico, al mostrar que dicha universalidad conduce, en la práctica política, a la extensión del derecho a toda la humanidad. El Estado representa la universalidad ética, en cuanto se ordena en la federación de Estados de la humanidad. El ideal del derecho al que alude Cohen es la humanidad misma, idea que tiene su manifestación concreta en la organización jurídica, democrática y socialista de todos los hombres.

\section{Conclusiones}

Ricardo Lagos, actual presidente de Chile, señalaba en un reciente artículo que las leyes de amnistia, los indultos y otras disposiciones de esta clase, que benefician a los que cometieron crímenes contra la humanidad, son muchas veces el precio que un Estado debe pagar para poder realizar la transición a la democracia. ${ }^{27}$

Es muy cierto que la transición a la democracia supone, en la generalidad de los casos, una negociación con los dictadores y que éstos buscan ansiosamente la impunidad para sus crimenes, con lo que dicha impunidad puede convertirse en una concesión aceptada por la sociedad. Ahora bien, es importante reconocer que esta decisión es forzada e impuesta por la violencia. Podemos decir que asegurarse la impunidad es la última forma de violencia que ejerce una dictadura contra el pueblo, pero que es, a la vez, una de las más duraderas y sutiles.

El juzgamiento extraterritorial, en tales casos, disminuye sin duda la soberanía del Estado. Pero ese juzgamiento extraterri- torial significa, en verdad, un restablecimiento de la soberanía del pueblo, pues el pueblo hubiera preferido juzgar a los criminales de no ser por la mayor violencia que éstos, todavía, están en posición de utilizar para evitar el castigo.

Si el concepto de soberanía se limitase a este último sentido, el de soberanía del pueblo, no habría, como querían Cohen y Kelsen, ninguna oposición entre el Estado y el derecho internacional. La voluntad popular y democrática de un Estado es, en el caso, llevada a su ejecución por los tribunales de otro Estado, que actúan como organismos del derecho internacional. Frente a esta situación es muy curioso que, sin embargo, algunas de las víctimas de la violencia - directa o indirecta - ejercida por los criminales contra la humanidad se indignen y opongan de manera exaltada al juzgamiento extraterritorial. Su motivación no puede sino ser explicada, según sostuve en la Introducción, como un tipo de fenómeno psicológico que les impide admitir haber sido victimados. En caso contrario, no cabe duda de que el juzgamiento extraterritorial debería ser aplaudido unánimemente por los partidarios de la democracia, desde el momento en que los dictadores locales no pueden ejercer violencia directa o indirecta sobre los tribunales del otro Estado, que se ha decidido a actuar como organismo del derecho internacional. Concedamos que, como se dijo, la impunidad es muchas veces el precio a pagar para la transición a la democracia y que, a fin de evitar males mayores, se les conceda esa garantía a los criminales ¿Por qué oponerse a que esos mismos criminales sean juzgados por los tribunales de un Estado sobre el cual no pueden ejercer ninguna violencia? ¿No es esto lo que les hubiera ocurrido a los criminales en su propio país, si no fuera porque aún conservan el recurso a las armas y la intimidación?

Más allá de la motivación psicológica para estas posiciones, el argumento prin- 
cipal empleado por los partidarios de la democracia para oponerse al juzgamiento extraterritorial es, según se ha visto en este trabajo, el que gira en torno a la noción de soberanía. A mi juicio, la crítica más demoledora contra esta noción es la que surge de las obras de Cohen y Kelsen, tal como he intentado exponerla aquí. Sobre la vinculación entre los dos autores quisiera también formular una síntesis y conclusión de lo que se ha dicho.

Volvamos entonces, brevemente, a la relación entre el pensamiento de Cohen y la obra de Kelsen, relación que, como mencionaba más arriba, tiende a subestimarse en ocasiones. ${ }^{28}$ Creo que está fuera de duda la defensa, por parte del último, de una posición universalista en la ética y en la teoría jurídica. El carácter "universalista" de la teoría pura del derecho es, por otro lado, afirmado por Kelsen de manera explícita ${ }^{29}$ en su obra más popular. que lleva el mismo nombre de su doctrina, la Teoría pura del derecho editada en 1934, una obra donde debe notarse que, con todo, muchos de sus puntos de vista son simplificados, así como limadas sus aristas más polémicas, a los fines de la difusión.

También vale la pena destacar que el universalismo de la teoría pura del derecho tiene como punto de partida, al igual que la ética de Cohen, una concepción sobre el sujeto. Dicha concepción se formula en términos que, a su vez, remiten claramente a las ideas de Cohen sobre la correlación entre el "yo" y el "otro", como puede notarse en el siguiente pasaje, tomado de la obra de Kelsen citada en último término:

El subjetivismo, que para concebir al mundo parte del propio yo, y extendiendo éste hasta el universo no puede llegar, sin embargo, por encimá del yo soberano a un mundo objetivo, es incapaz de concebir a un otro sujeto, al no- yo que se presenta con la misma pretensión de soberania, al "tú" que también quiere ser un yo, como una entidad de la misma especie que el propio yo. ${ }^{30}$
La crítica de Kelsen al subjetivismo no tiene, por cierto, el grado de complejidad y precisión al que llega Cohen. Que la terminología de Kelsen no era enteramente correcta desde el punto de vista técnico- filosófico, tanto más cuanto se la compara con la de los filósofos de Marburgo, era algo que aquél reconocía sin ningún problema, "gustosamente" incluso. ${ }^{31}$ Lo que debe subrayarse, en cambio, es que, basado en la concepción del sujeto expuesta, construye Kelsen un punto de vista sobre el derecho que tiene como hipótesis fundamental la pluralidad intersubjetiva, cuyo carácter a priori es afirmado, también, de manera explícita. ${ }^{32}$

La idea de intersubjetividad corresponde, en el plano jurídico, a la representación de una pluralidad de Estados que se reconocen recíprocamente como sujetos, teniendo este reconocimiento recíproco un carácter fundamental, vale decir, no derivado. La personalidad jurídica es así intersubjetiva de manera a priori. Esta idea se identifica, como se dijo más arriba, con la humanidad, en cuanto "ideal ético más alto". Kelsen agrega que la noción de la prioridad de la comunidad jurídica de los Estados, frente a cada uno de éstos, fue formulada, en primer lugar, por el clásico del iusnaturalismo alemán Christian Wolff como la teoría de una civitas maxima, esto es, de una comunidad jurídica mundial.

Wolff entendía que el derecho internacional se funda en una comunidad jurídica del derecho natural, la cual abarca a todos los Estados, con independencia de su consentimiento. Esta comunidad es la que denomina civitas maxima. Justamente por ser sujetos de esta comunidad juridica del derecho natural, pueden los Estados realizar pactos entre sí, los que dan origen a un derecho internacional particular y positivo. Esto coincide plenamente con la tesis tanto de Cohen como de Kelsen, de acuerdo con la cual la constitución de la personalidad jurídica no depende de la 
voluntad psicológica de la persona, sino que debe presuponerse para que puedan, en general, existir normas jurídicas. ${ }^{33}$

Desde esta intersubjetividad fundamental, tanto Cohen como Kelsen llegan a ver que el derecho debe concebirse, en última instancia, como derecho de toda la humanidad, lo que se opone de manera radical a la noción de soberanía del Estado, de la que aún no hemos conseguido librarnos en nuestros días. Ambos autores desarrollan así un mismo programa teórico, donde el universalismo de la ética es puesto en práctica para el análisis e interpretación de instituciones jurídicas, conformando, finalmente, el proyecto conceptual para su transformación.

En el pasaje final de su principal obra sobre la soberanía, ya citada más de una vez en estas páginas, expresa Kelsen el ideal, típicamente neokantiano, de una comunidad jurídica internacional plenamente desarrollada, el ideal ético más alto de la humanidad. Con estas palabras me gustaría terminar también el presente artículo:

La representación de la soberanía tiene que ser, claro está, eliminada desde la raíz ¡Esta revolución de la consciencia cultural es, ante todo, necesaria! No meramente a los fines de una construcción jurídica - aunque la perspectiva correcta en la teoría jurídica puede eliminar muchos obstáculos para el desarrollo del derecho. Pues la representación de la soberanía del propio Estado se ha cruzado, hasta ahora, en el camino de todo lo que tiende - también en el sentido político de esta palabra - a una conformación del derecho internacional como una organización diferenciada, a la creación de órganos especializados para la creación, aplicación y ejecución del derecho internacional, al desarrollo de la comunidad jurídica internacional desde su situación de primitivismo hasta una civitas maxima. Pero como una infinita tarea tiene que ser el Estado mundial, en cuanto organización del mundo, dado a toda aspiración política. ${ }^{34}$

\section{BIBLIOGRAFÍA}

Bulygin, Eugenio (1991), "Validez y positivismo" (publicado originariamente en Segundo Congreso Internacional de Filosofía del Derecho, La Plata, 1987 y en versión reelaborada con el título "An Antinomy in Kelsen's Pure Theory of Law" en: Ratio Juris, 3 (1990) pp. 29- 45, ahora en: Carlos Alchourrón, Eugenio Bulygin, Análisis lógico y Derecho, Centro de Estudios Constitucionales, Madrid, 1991, pp. 499-519.

Calsamiglia, Albert (1996), "Ciencia jurídica", en: Ernesto Garzón Valdés / Francisco Laporta (eds.), El derecho y la justicia. Volumen 11 de la Enciclopedia Iberoamericana de Filosofía, Trotta, Madrid, 1996, pp. 17- 27.

Cohen, Hermann: las obras de Cohen se citan según las obras completas (Werke), editadas por el Archivo-Hermann- Cohen en el Institutuo de Filosofía de la Universidad de Zürich, bajo la dirección de Helmut Holzhey, Hildesheim - New York, Georg Olms, 1977 y ss.

- Logik der reinen Erkenntnis (1902), $1^{\mathrm{a}}$ edición Berlin 1902 - $2^{\mathrm{a}}$ edición, Berlin, Bruno Cassirer, 1918 (Werke, tomo 6, $1^{\text {a }}$ parte, 1977).

- Ethik des reinen Willens (1904), - $1^{\text {a }}$ edición Berlin 1904 - $2^{a}$ edición, Berlin, Bruno Cassirer, 1907 (Werke, tomo 7, 2 ${ }^{\mathrm{a}}$ parte, 1981).

Daza Valenzuela, Pedro, "Pinochet y la soberanía chilena", Nueva Sociedad (Caracas), $\mathrm{n}^{\circ} 161,1999$, pp. 77-81.

Edel, Geert (1988), Von der Vernunftkritik zur Erkenntnislogik. Die Entwicklung der theorethischen Philosophie Hermann Cohens, Freiburg/München, Karl Alber, 1988.

Ferraro, Agustín (2000), La ética del positivismo jurídico. Estudio sobre la influencia de la ética universalista de Hermann Cohen en la teoría pura del derecho de Hans Kelsen, Buenos Aires, Eudeba, 2000. 
Guibourg, Ricardo (1996), "Los conceptos jurídicos fundamentales en la teoría pura del derecho", Anuario de Filosofía Juridica y Social, $\mathrm{n}^{\circ} 16$ (1996), pp. 33-50.

Holzhey, Helmut (1984), "Die Transformation neukantianischer Theoreme in die Reine Rechtslehre Kelsens", Archiv für Rechts- und Sozialphilosophie, Beiheft 20 (1984), pp. 96-110.

Kant, Immanuel: las obras de Kant se citan según la edición de Wilhelm Weischedel en XII tomos (Frankfurt am Main, Insel, 1964 y ss.), reimpresión Frankfurt am Main, Suhrkamp, 1977 y ss. Se han utilizado las denominaciones abreviadas de uso habitual en la literatura especializada:

- Zum ewigen Frieden. Ein philosophis cher Entwurf ( $1^{\mathrm{a}}$ edición Königsberg 1795), tomo XI, pp. 195-251.

- Kritik der reinen Vernunft ( $1^{\text {a }}$ edición Riga 1781), tomos III y IV.

Kelsen, Hans, (1920), Das Problem der Souveränität und die Theorie des Völkerrechts. Beitrag zu einer reinen Rechtslehre $\left(1^{\mathrm{a}}\right.$ edición Tübingen 1920$), 2^{\mathrm{a}}$ reimpresión de la $2^{\mathrm{a}}$ edición Tübingen 1928 , Aalen, Scientia, 1981.
- (1923) Hauptprobleme der Staatsrechtslehre. Entwickelt aus der Lehre vom Rechtssatze $2^{\mathrm{a}}$ reimpresión de la $2^{\mathrm{a}}$ edición Tübingen 1923, Aalen, Scientia, 1984.

- (1934), Reine Rechtslehre. Einleitung in die rechtswissenschaftliche Problematik, $2^{\mathrm{a}}$ reimpresión de la $1^{\mathrm{a}}$ edición Leipzig y Viena 1934, Aalen, Scientia, 1994.

Lagos, Ricardo / Muñoz, Heraldo, "El dilema Pinochet", Nueva Sociedad (Caracas), $\mathrm{n}^{\circ} 161,1999$, pp. 70-76.

Nino, Carlos (1980), Introducción al análisis del derecho, Buenos Aires, Astrea, $2^{\mathrm{a}}$ edición 1980 ( $1^{\mathrm{a}}$ edición 1973$)$.

Paulson, Stanley (1994), "Vorwort zum Neudruck", en: Hans Kelsen, Reine Rechts lehre. Einleitung in die rechtswissenschaftliche Problematik, $2^{\mathrm{a}}$ reimpresión de la $1^{\mathrm{a}}$ edición Leipzig y Viena 1934, Aalen, Scientia, 1994, pp. III-VIII.

- (1994a), "Kelsen and the Marburg School: Reconstructive and Historical Perspectives", en: W. Krawietz/ N. MacCormik/ G.H. von Wright (eds.) Prescriptive Formality and Normative Rationality in Modern Legal Systems, Berlin, Duncker \& Humblot, 1994

\begin{abstract}
${ }^{1}$ La llamada "obediencia debida" sancionada en Argentina por ley nacional, que representa una doctrina insostenible desde el punto de vista ético.

2 Además de esta preocupación por la soberania, cabe mencionar un factor psicológico adicional, que se manifiesta en el extraño entusiasmo con que algunos - siendo indudables partidarios de la democracia se han opuesto al juzgamiento extraterritorial de antiguos dictadores y terroristas de Estado. Se trata, a mi juicio, de la dificultad para reconocer haber sido víctima de actos de violencia psicológica por parte de esos mismos criminales. Asî por ejemplo. Alfonsín, Menem, sus partidarios y admiradores, nunca reconocieron francamente que las leyes eximentes de responsabilidad o los indultos fueron una imposición de los militares, resultado directo de sublevaciones y amenazas notorias, frente a las cuales resultó más o menos inevitable hacer concesiones. La necesidad de esas concesiones no se pone aquí en duda, sino que me interesa
\end{abstract}

destacar el hecho - sorprendente - de que las concesiones han sido presentadas por los gobernantes democráticos como actos plenamente voluntarios, en los que ninguna coerción estuvo en juego. Consistentemente con esto, la necesidad de un juicio extraterritorial, fundada en que los criminales no fueron debidamente juzgados o no cumplieron sus condenas - por haber logrado intimidar exitosamente a la sociedad y a sus gobernantes - es rechazada con indignación por algunos demócratas, que nunca admiten haber sufrido tal violencia.

${ }^{3}$ Kant, Zum ewigen Frieden, 225.

${ }^{4}$ Kelsen 1920,172 (mi traducción en todas las citas).

${ }^{5}$ Vd. Bulygin 1991, 502, Calsamiglia 1996, 21, Nino 1980, 40, Guibourg 1996, 35.

6 Daza Valenzuela 1999, 81.

${ }^{7}$ Daza Valenzuela 1999, 79.

\& Daza Valenzuela 1999, 81. 
9 El Estatuto de Roma es la base legal de la Corte Penal Internacional permanente, adoptado por un Conferencia Diplomática (convocada por la Asamblea General de la ONU) reunida en Roma desde el 15 de junio al 17 de julio de 1998. El Estatuto de Roma entrará en vigor el primer día del mes siguiente $60^{\circ}$ día del depósito del $60^{\circ}$ instrumento de ratificación aprobación, aceptación o accesión, en la sede de las Naciones Unidas de Nueva York.

10 La razón por la que debe considerarse a la soberanía como una ficción juridica ha sido ya expuesta en la práctica de las relaciones internacionales los Estados débiles son avasallados en su voluntad con gran frecuencia.

${ }^{11}$ Kelsen 1920, 315

12 Kelsen, 1920, 317

${ }^{13}$ Kelsen, 1920, 204

Kelsen, 1920, 274

15 Una exposición y análisis detallados de la filosofia teórica de Cohen se encontrará en Edel 1988. Para una exposición más elemental, en lengua castellana, me permito remitir a mi propio Ferraro 2000

${ }^{16}$ Cit. en Cohen 1904, 208

${ }^{17}$ Cohen 1904, 212

18 Vd. Kant, Kritik der reinen Vernunft, B 140
19 Kelsen 1923, XVIII.

${ }^{20} \mathrm{Vd}$. Holzhey 1984

${ }_{21}$ Vd. Paulson 1994, V.

${ }^{22}$ Una vez más, me permito remitir al lector a $\mathrm{m}$ trabajo sobre Cohen (Ferraro 2000), en cuyos capítulos II y III discuto el carácter del método ético-trascendental de Cohen y la deducción de la autoconsciencia ${ }^{23}$ Cohen, 1904, 248.

${ }^{24} \mathrm{La}$ idea del acto de habla refleja muy bien lo que Cohen quiere decir aqui: cuando uno habla, le habla a alguien. Se puede también hablarse a sí mismo pero esta práctica resulta derivada, en cuanto uno se dirige a sí mismo como si le hablase a un otro. La figura del otro, como el "tú" de la ilocución, resulta por esto, pragmáticamente necesaria.

25 Cohen, 1904, 82

${ }^{26}$ Cohen, 1904, 495-497.

${ }^{27}$ Lagos/Muñoz 1999, 73.

28 Vd. Paulson 1994a.

${ }^{29}$ Kelsen 1934, 59.

${ }^{30}$ Kelsen, 1934, 142.

31 Kelsen 1922, 375.

${ }^{32}$ Kelsen, 1920, 252

${ }^{33}$ Vd. Kelsen, 1920, pp. 250-251.

${ }^{34}$ Kelsen, 1920, 320 